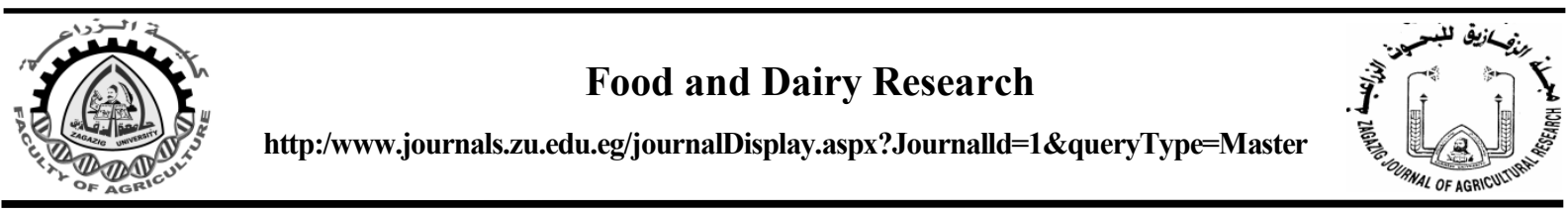

\title{
ANTIOXIDANT ACTIVITY OF APPLE PEEL EXTRACTS PREPARED BY DIFFERENT SOLVENTS
}

\author{
Ahmed E. Hegazy* \\ Food Sci. and Technol. Dept., Fac. Agric., Al-Azhar Univ., Cairo, Egypt
}

Received: 07/11/2017 ; Accepted: 03/12/2017

\begin{abstract}
Crude extracts of applee peel were prepared by soxhelt extraction method with solvents methanol, ethanol, dichloromethane, acetone, hexane and ethyl acetate. Extracts were subjected for the measurement of total phenolic content (TPC) by Folin-Ciocalteu method as well as flavonoid content, chelating activity, reducing power and antioxidant/radical scavenging activity [1,1diphenyl-2-picryl-hydrazyl (DPPH) free radical scavenging activity]. Results for all samples were in agreement with each other. The results revealed that all extracts of the apple peel exhibit antioxidant activity. These findings suggest that the apple peel extracts could act as potent source of antioxidants.
\end{abstract}

Key words: Apple peel, antioxidant activity, phenolic contents, flavonoids.

\section{INTRODUCTION}

Fruits and vegetables can be considered as an ideal source of natural antioxidants. It is credible to speculate that increasing consumption of these fruits intentionally will increase the intake of natural antioxidants, which may provide an alternative in the intervention of the aging process by protecting against oxidative damage. Various fruits may provide protection differently against oxidative stress since they are different in antioxidant capacity. We hypothesize that fruits with high antioxidant capacity are more effective than those with low antioxidant capacity in reducing oxidative damage associated with the aging process. Fruits are rich in antioxidants that help in lowering incidence of degenerative diseases such as cancer, arthritis, arteriosclerosis, heart disease, inflammation, brain dysfunction and acceleration of the ageing process. Antioxidants are substances which when present at low concentration are able to prevent or delay oxidative damage of lipids, proteins and nucleic acids by reactive oxygen species. These reactive oxygen species mainly are reactive free radicals such as superoxide, hydroxyl, peroxyl, alkoxyl and non- radicals such as hydrogen peroxide, hypochlorous. They

\footnotetext{
* Corresponding author: Tel. : +201004164429

E-mail address: ahmedhegazyh@yahoo.com
}

scavenge radicals by inhibiting initiation and breaking chain propagation or suppressing formation of free radicals by binding to the metal ions, reducing hydrogen peroxide, and quenching superoxide and singlet oxygen (Shi et al., 2001).

One of the examples of fruit that contains high antioxidant contents is apple. It is important source of flavonoids and phenols which is consumed during whole year. Consumption of apples has been linked with the prevention of chronic diseases and with a lower incidence of cancer (Jakopic et al., 2009). Apple consumption has also been associated with a decreased risk of coronary heart disease in women (Sesso et al., 2003). Apples contain many types of phenolic derivates and flavonoids. Moreover, the concentration of phenolic compounds may be affected by apple, cultivar and genus and also by extrinsic factors, such as soil, seasonality, agronomic factors, light exposure, etc. (Vieira et al., 2011) Apple polyphenols have various in vitro bioactivities (i.e., reduced risk of coronary heart disease.It is highly beneficial for our health due to its medicinal properties that act against diseases associated with oxidation and anti-aging (Balboa et al., 2013). 
The purpose of this study was to evaluate apple peel as new potential source of natural antioxidants. In this study, the extracts of apple peel were prepared in methanol, ethanol, dichloromethane, acetone, hexane and ethyl acetate by soxhelt continuous extraction; The antioxidant activity of the extracts was assessed by modification of established assays, such as total phenolic content by Folin-Ciocalteu reagent; total flavonoids content, chelating activity by 2,2 . bipyridyl competition assay; antioxidant activity as free radical scavenging by $\mathrm{DPPH}$ and reducing power.

\section{MATERIALS AND METHODS}

\section{Chemicals and Reagents}

Folin-Ciocalteu reagent, methanol, ethanol, dichloromethane, acetone, hexane and ethyl acetate were purchased from E. Merck. Ferrous sulphate, Disodium ethylenediaminetetraacetate (Na2EDTA), and butylated hydroxyanisole (BHA), were purchased from Fluka Riedel-de Haën. Quercetin, Gallic acid, 2,2-bipyridyl, HCl and 2,2-diphenyl-1-picrylhydrazyl (DPPH) were purchased from Sigma-Aldrich $\mathrm{GmbH}$, Germany. All other chemicals and solvents were of the highest analytical grade and used as supplied.

\section{Preparation of Extracts}

Egyptian Anna apple (Malus domestica Borkh) fruits were harvested at Nubaria city, Egypt. Apples were washed, separated into peels and sliced into small pieces. The sample was oven dried at $50-60^{\circ} \mathrm{C}$ to constant weight (Duh et al., 1999).

\section{Yield Estimation}

Yield was estimated by reported method of Prashani et al. (2005). Each extract $(10 \mathrm{ml})$ was measured into a pre-weighed aluminum dish. The samples were kept in an oven at $85^{\circ} \mathrm{C}$ for 24 hours then followed by placing in desiccator for 12 hours. The weight difference was used to calculate percentage yield as well as expressed in $\mathrm{mg} / 10 \mathrm{ml}$.

\section{Determination of total flavonoid content}

Colorimetric aluminum chloride method was used for flavonoid determination (Ebrahimzadeh et al., 2008). Briefly, $0.5 \mathrm{ml}$ solution of each plant extracts in methanol were separately mixed with $1.5 \mathrm{ml}$ of methanol, $0.1 \mathrm{ml}$ of $10 \%$ aluminum chloride, $0.1 \mathrm{ml}$ of $1 \mathrm{M}$ potassium acetate, and $2.8 \mathrm{ml}$ of distilled water, and left at room temperature for 30 minutes. The absorbance of the reaction mixture was measured at $415 \mathrm{~nm}$ with a double beam Perkin Elmer UV/Visible spectrophotometer (USA). Total flavonoid contents were calculated as quercetin from a calibration curve. The calibration curve was prepared by preparing quercetin solutions at concentrations 12.5 to 100 mg ml-1 in methanol.

\section{Determination of total phenolic content}

Total phenolic compounds were determined by the Folin-Ciocalteau method (Ebrahimzadeh et al., 2008). The extracted samples $(0.5 \mathrm{ml}$ of different dilutions) were mixed with Folin Ciocalteu reagent $(5 \mathrm{ml}, 1: 10$ diluted with distilled water) for $5 \mathrm{~min}$ and aqueous $\mathrm{Na}_{2} \mathrm{CO}_{3}$ $(4 \mathrm{ml}, 1 \mathrm{M})$ were then added. The mixture was allowed to stand for $15 \mathrm{~min}$ and the phenols were determined by colorimetry at $765 \mathrm{~nm}$. The standard curve was prepared by $0,50,100,150$, 200 , and $250 \mathrm{mg} \mathrm{ml}-1$ solutions of gallic acid in methanol: water $(50: 50, V / V)$. Total phenol values are expressed in terms of gallic acid equivalent (mg g-1 of dry mass), which is a common reference compound.

\section{DPPH radical-scavenging activity}

Free radical scavenging capacity of apple peel extracts was determined according to the previous reported procedure using the stable 2 , 2-diphenyl-1- picrylhydrazyl radical (DPPH) (Ali et al., 2001). Briefly, a freshly prepared DPPH solution in ethanol $(0.5 \mathrm{ml})$ was added to $3 \mathrm{ml}$ of diluted each apple peel extract to start the radical antioxidant reaction. The final concentration was $100 \mu \mathrm{M}$ for $\mathrm{DPPH}^{\circ}$. The decrease in absorbance was measured at different intervals, i.e. $0,0.5,1,2,5,10$ and 15 min. up to $50 \%$ at $517 \mathrm{~nm}$. The remaining concentration of DPPH in the reaction mixture was calculated from a standard calibration curve. The absorbance measured at $5 \mathrm{~min}$ of the antioxidant-DPPH radical reaction was used to compare the DPPH radical scavenging capacity of each extract. 
DPPH remaining $(\%)=[\mathrm{DPPH}] \mathrm{T} /[\mathrm{DPPH}] \mathrm{T}=0$ $\times 100$

Where: $\mathrm{T}$ is the time interval.

\section{Reducing power ability (RPA)}

The reducing power of apple peel extracts was quantified by the method described previously (Perumal and Klaus, 2003) with minor modification. apple peel extract $(0,1.0$, $2.0,3.0,5.0,7.0,9.0,11.0 \mathrm{mg}$ ) disolved in $1 \mathrm{ml}$ of $80 \%$ methanol were mixed with phosphate buffer $(5.0 \mathrm{ml}, 2.0 \mathrm{M}, \mathrm{pH} 6.6)$ and potassium ferricyanide $(5.0 \mathrm{ml}, 1.0 \%)$; the mixtures were incubated at $50^{\circ} \mathrm{C}$ for $20 \mathrm{~min}$. A portion $(5.0 \mathrm{ml})$ of trichloroacetic acid (10\%) was added and the mixture was centrifuged at $3000 \mathrm{rpm}$ for $10 \mathrm{~min}$. The upper layer of the solution $(5.0 \mathrm{ml})$ was mixed with distilled water $(5.0 \mathrm{ml})$ and ferric chloride $(1.0 \mathrm{ml}, 0.1 \%)$, and than absorbance of the pink colour mixture was measured spectrophotometrically at $700 \mathrm{~nm}$. Increased absorbance of the mixture indicates increased reducing power. The experiment was conducted in triplicate and results were averaged.

\section{Chelating activity}

Chelating activity $\left(\mathrm{Fe}^{+2}\right)$ was measured by 2 , 2 '-bipyridyl competition assay (Pellegrini et al., 1999). The reaction mixture containing $0.25 \mathrm{ml}$ of $\mathrm{FeSO}_{4}$ solution $(1 \mathrm{mM}), 0.25 \mathrm{ml}$ of antioxidant solution, $1 \mathrm{ml}$ of Tris- $\mathrm{HCl}$ buffer

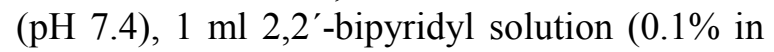
$0.2 \mathrm{M} \mathrm{HCl}$ ) and $2.5 \mathrm{ml}$ of ethanol. The final volume was made up $6.0 \mathrm{ml}$ with distilled water. The absorbance was measured at $522 \mathrm{~nm}$ and used to evaluate $\mathrm{Fe}^{+2}$ chelating activity using disodium ethylene diamine tetracetate (Na2EDTA) as a standard.

\section{Statistical Analysis}

The results of this investigation are means of five measurements. To verify the statistical significance of all parameters the values of means_SD were calculated. To compare several groups, analysis of variance (ANOVA) was used. In the assessment of TRAP, the Spearman correlation coefficient (R) and P-value were used to show correlations and their significance. Linear regressions were also calculated. The $\mathrm{P}$ values of $<0.05$ were adopted as statistically significant (Steel and Torrie, 1980).

\section{RESULTS AND DISCUSSION}

The yield of the extracts obtained by the soxhelt method was calculated as percent by weight of the apple peel. According to the chemical composition and polar nature of phenolic compounds, apple contains a relatively high percentage yield in ethanol and methanol while lower in hexane. Percentage yields in ethanol and methanol are comparable but have slight difference as shown in Table 1.

The phenolic compounds may contribute directly to the antioxidant action therefore, it is necessary to investigate total phenolic content. The total phenolic content was determined by following a modified Folin-Ciocalteu reagent method. In Table 2 the results were expressed as gallic acid equivalent. TPC was in the range of $63.90-170.56 \mathrm{mg} / \mathrm{g}$ of the apple peel extracts. The amounts of total phenolic compounds were higher $(\mathrm{p}<0.05)$ in ethanol extract $(170.56 \mathrm{mg} / \mathrm{g})$ while they were lowest $(p<0.05)$ for hexane $(63.90 \mathrm{mg} / \mathrm{g})$. Using a standard curve of gallic acid $(R 2=0.999)$. All results coincide with those of total antioxidant capacity. In other words, the spice extract sample shows a tendency to have high phenolic content.

Using the $\mathrm{AlCl} 3$ reagent and quercetin as standard $(\mathrm{R} 2=0.9996)$, the total flavonoids are in the range from 14.89-31.75 $\mu \mathrm{g} / \mathrm{g}$ of quercetin equivalent (Table 2$)$. The highest value ( $\mathrm{p}<0.05)$ for the ethanol was $31.75 \mu \mathrm{g} / \mathrm{g}$ and the lowest $(\mathrm{p}<0.05)$ was $14.89 \mu \mathrm{g} / \mathrm{g}$ of the apple peel with the following decreasing order of the extract ethanol $>$ methanol $>$ acetone $>$ ethyl acetate $>$ dichloromethane $>$ hexane. Flavonoids are not easily detectable therefore, in the extract $\mathrm{AlCl} 3$ was used as complexing reagent.

The chelating activity was measured against $\mathrm{Fe}^{+2}$ and reported as EDTA equivalents as shown in Table 2 . The difference $(p<0.05)$ in chelating activity was observed among the extract. The highest chelating activity was observed in ethanol. The EDTA equivalent was in the range of $1097-575 \mu \mathrm{g} / \mathrm{g}$ of apple peel extracts (Table 2).

According to Ilhami et al. (2005) metal chelating capacity is significant since it reduces the concentration of catalyzing transition metal 
Ahmed E. Hegazy

Table 1. Percentage yield of apple peel extract in different organic solvents as well as in $\mathbf{m g} / 10 \mathrm{ml}$.

\begin{tabular}{lcc}
\hline Organic solvent & Yield $\mathbf{~ m g ~ / ~} \mathbf{~} \mathbf{~ m l}$ & Yield of apple peel extract (\%) \\
\hline Methanol & 70.27 & 29.32 \\
Ethanol & 66.82 & 28.96 \\
Dichloro methane & 35.79 & 14.29 \\
Acetone & 49.90 & 18.91 \\
Hexane & 22.76 & 9.27 \\
Ethyl acetate & 59.27 & 25.92 \\
\hline
\end{tabular}

Table 2. Total phenolic content (TPC), flavonoid content (FC) and chelating activity of organic solvent extracts of apple peel expressed as gallic acid, quercetin and Na2EDTA equivalent, respectively

\begin{tabular}{lccc}
\hline Sample & $\begin{array}{c}\text { TPC gallic acid eq. } \\
(\mathbf{m g} / \mathbf{g} \text { of apple peel) }\end{array}$ & $\begin{array}{c}\text { FC Quercetin eq. }(\boldsymbol{\mu g} / \mathbf{g} \\
\text { of apple peel) }\end{array}$ & $\begin{array}{c}\text { Chelating activity EDTA } \\
\text { eq }(\boldsymbol{\mu g} / \mathbf{g} \text { of apple peel) }\end{array}$ \\
\hline Methanol & 165.58 & 28.56 & 1093 \\
Ethanol & 170.56 & 31.75 & 1099 \\
Dichloro methane & 98.94 & 17.89 & 784 \\
Acetone & 149.79 & 22.87 & 1031 \\
Hexane & 63.90 & 14.89 & 579 \\
Ethyl acetate & 86.27 & 18.96 & 794 \\
\hline
\end{tabular}

Data are mean $(\mathrm{n}=3) \pm \mathrm{SD}(\mathrm{n}=3),(\mathrm{p}<0.05)$.

in lipid peroxidation. Moreover, the chelating agents, which form ó-bonds with a metal, are effective as secondary antioxidants, because they reduce the redox potential thereby stabilizing the oxidized form of the metal ion, therefore it is an important parameter.

The antioxidant capacity of the apple peel extracts were analyzed by using the free radical scavenging $\left(\mathrm{DPPH}^{\circ}\right)$ and the ferric reducing antioxidant power (FRAP) methods. The $\mathrm{DPPH}^{\circ}$ test is the oldest indirect method for determining the antioxidant activity, which is based on the ability of the stable free radical 2, 2-diphenyl-1picrylhydrazyl to react with hydrogen donors including phenols. The decrease in absorbance of DPPH radical is caused by antioxidant through the reaction between antioxidant molecule and radical results in the scavenging of the radical by hydrogen donation. As Fig.1 illustrates a significant decrease $(p<0.05)$ in the concentration of DPPH due to scavenging activity of apple peel extract. Maximum difference among the extract was observed at 5 min of the reaction and the remaining amount (\%) of DPPH radical at 5 min after initiation of reaction as shown in Figure 2 was 78.14, 73.42, $62.06,65.38,58.78$ and 68.99 for ethanol, methanol, dichloromethane, acetone, hexane and ethyl acetate, respectively. The high amount of the phenolic compounds and reducing power having the highest percent DPPH scavenging activity was shown by the ethanol extract, and the second highest activity was determined in the methanol while lowest in hexane. 


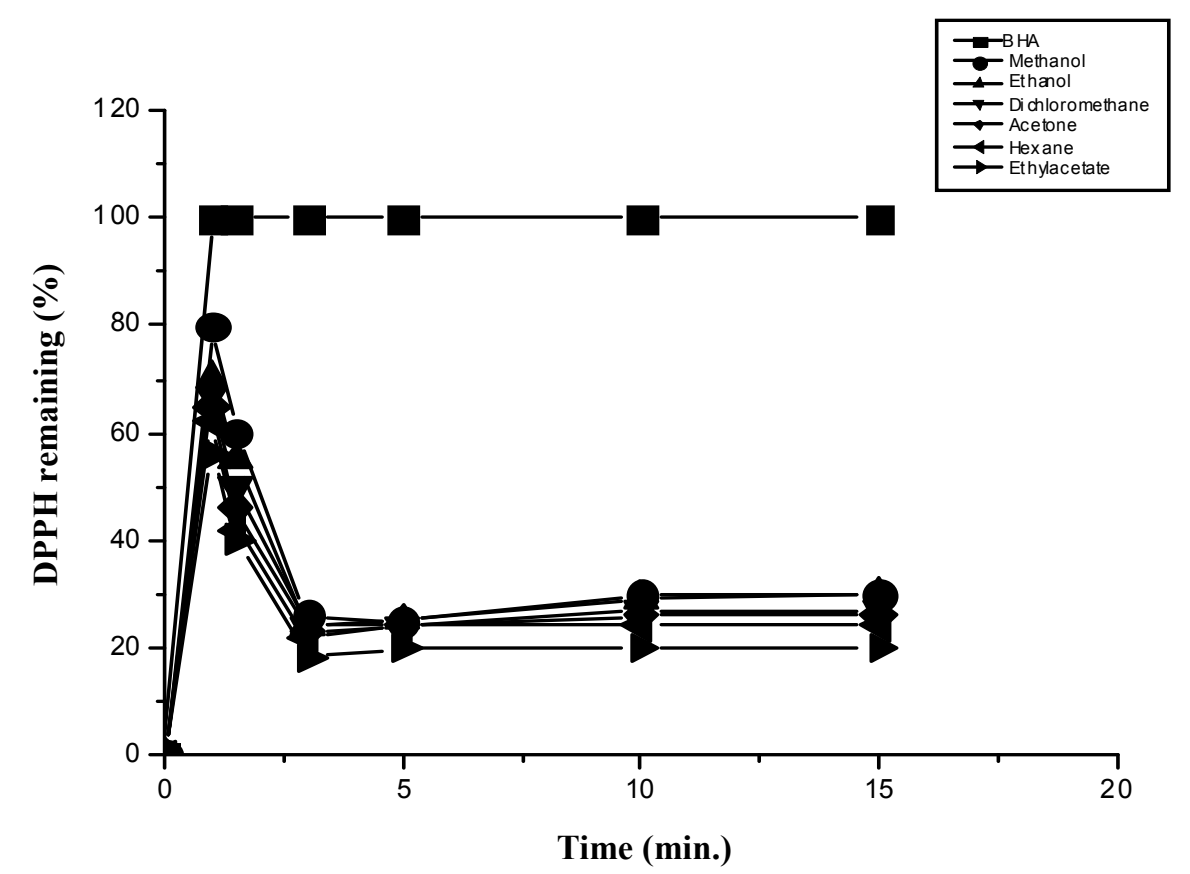

Fig. 1. Kinetic behavior of radical scavenging activity of cumin extracts as assayed by the DPPH method. The final DPPH concentration was kept $100 \mu \mathrm{M}$ in all reaction mixtures. Values are mean $(\mathbf{n}=3),(P<0.05)$

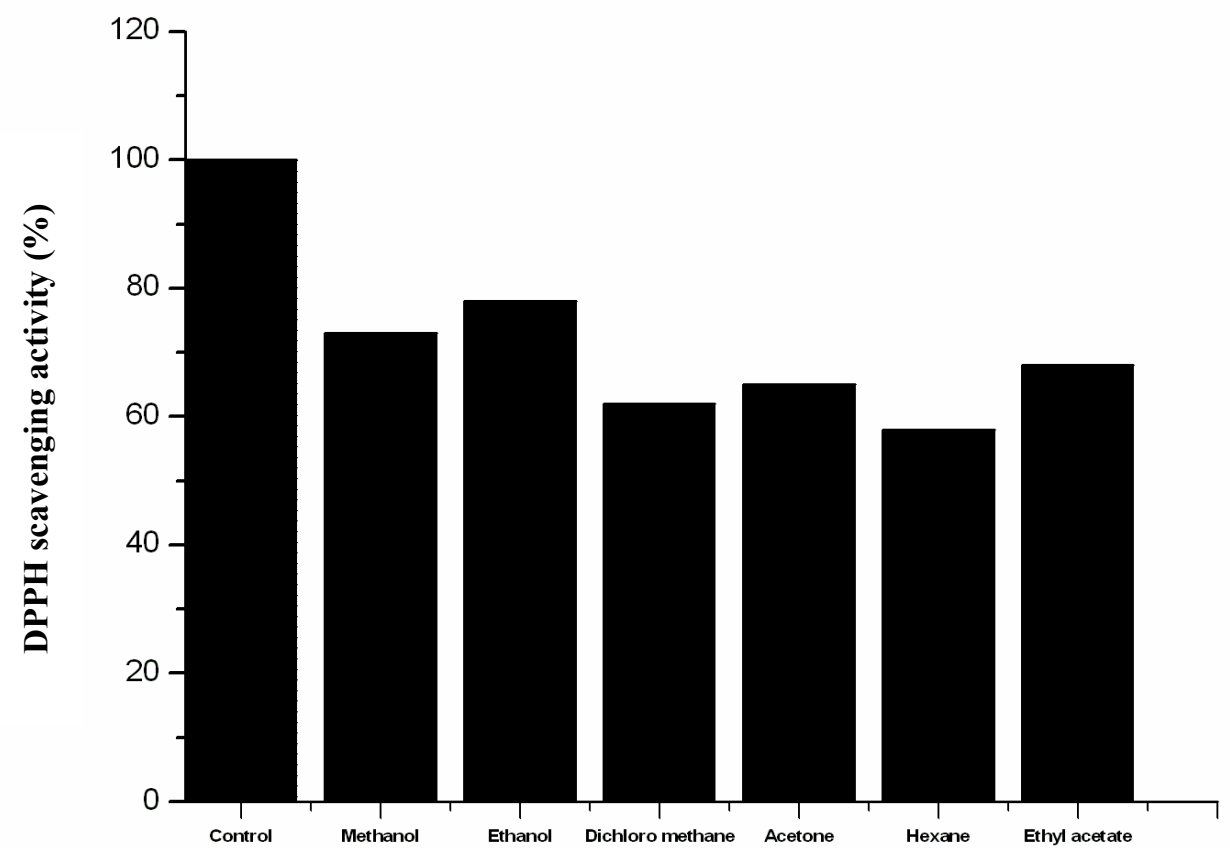

Fig. 2. DPPH radical scavenging activity of apple peel extract at $5 \mathrm{~min}$. Vertical bars represents the standard deviation of each data point. Values are mean $(n=3),(P<0.05)$ 
It has been reported that the reducing power of bioactive compounds is associated with antioxidant activity. Thus, it is necessary to determine the reducing power of phenolic constituents to elucidate the relationship between their antioxidant effects and there reducing power (Shan et al., 2005). The reducing power of the extracts increases $(\mathrm{P}<$ $0.05)$ with an increase in the amount of the extract as shown in Fig. 3. The amount of the phenolic compounds was high in ethanol extract of apple peel, therefore; similar results were obtained in reducing power activities. Hence, by correlating these results; we can suggest that there may be relationship between the amount of total phenolic content and reducing power.

The reducing power of the extracts was compared with a known reducing agent BHA. The reducing power of the extract was markedly lower $(\mathrm{P}<0.05)$ than that of BHA. However, among these extracts the ethanol extract of apple peel has shown the highest $(\mathrm{P}<0.05)$ reducing power.

\section{Conclusion}

From this stydy, it could be concluded that the solvent play a vital role in the extraction of the plant constituents. As methanol and ethanol are highly polar among the solvents used, therefore, they contain high yield of phenolic compounds as compared to the other solvents. An ethanolic extract of apple peel was shown highest antioxidant activity (\% DPPH scavenging activity). The antioxidant activity could be correlated with the polyphenolic components present in the extract. The results obtained from these methods provide some important factors responsible for the antioxidant potential of apple peel.

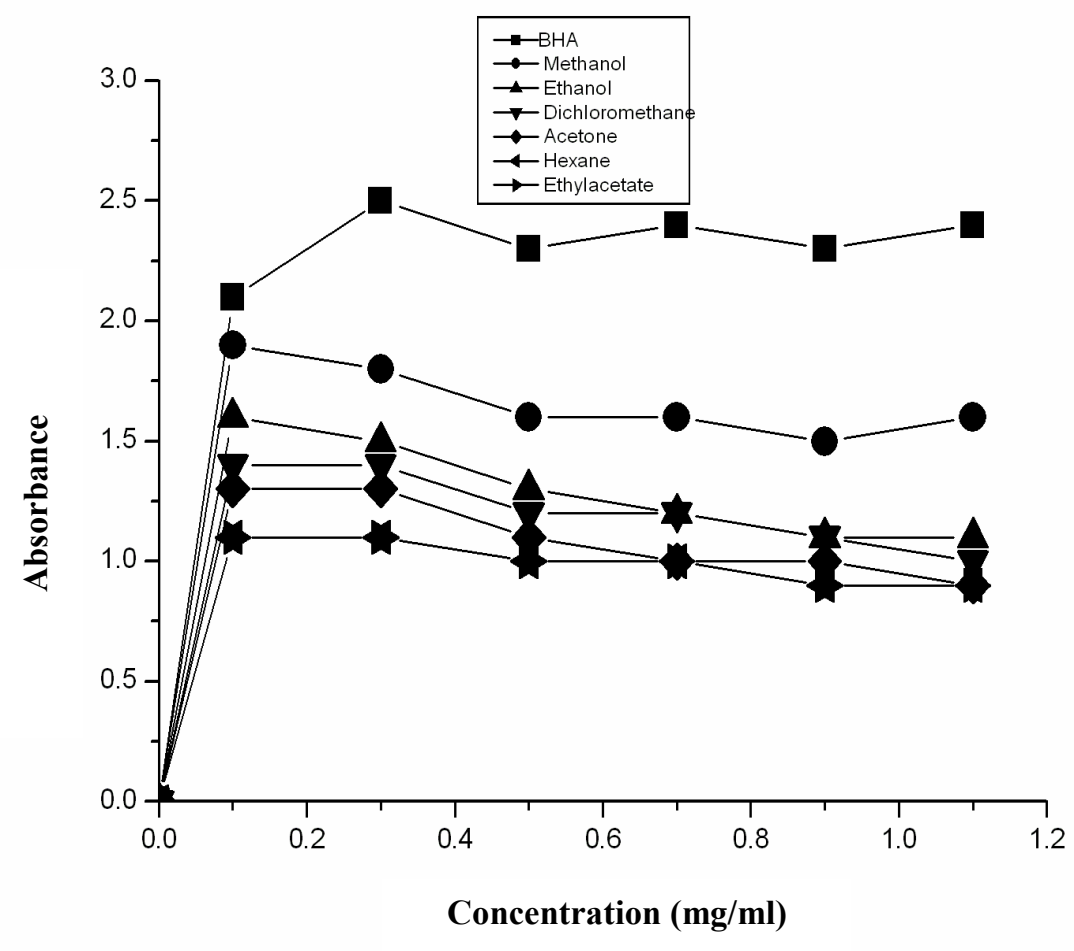

Fig. 3. Reducing power of ethanol, methanol, dichloromethane, acetone, hexane and ethyl acetate extract of apple peel. All data is reported as mean \pm S.D $(n=3)$ statistically significant as $\mathbf{P}<0.01$ 


\section{REFERENCES}

Ali, Y., M. Ahmet and A.K. Ayse (2001). Determination of antioxidant and antimicrobial activities of Rumex crispus L. extracts. J. Agric. Food Chem., 49: 4083.

Balboa, E.M., E. Conde, A. Moure, E. Falqué and H. Domínguez (2013). Food Chem., 138 (2-3): 1764-1785.

Duh, P.D., Y.Y. Tu and G.C. Yen (1999). Lebensmittel-Wissenschaft Technology, 32 (5): 269-2778, E. N. Frankel, Food Chem., 57 (1996): 51.

Ebrahimzadeh, M.A., S.J. Hosseinimehr, A. Hamidinia and M. Jafari (2008). Antioxidant and free radical scavenging activity of Feijoa sallowiana fruits peel and leaves. Pharmacologyonline, 1: 7-14.

Ilhami, G.A., A. Haci and C. Mehmet (2005). Chem. Pharm. Bull., $53: 281$.

Jakopic, J., F. Stampar and R. Veberic (2009). Scientific Hort., 123 (2): 234-239.

Prashani, M.E., T.P. Geun, D.L. Young, K. Sejae, J. Sang and L. Jehee (2005). J. Food Lipids., $12: 34$.
Perumal, S. and B. Klaus (2003). Antioxidant properties of various solvent extracts of total phenolic constituents from three different agroclimatic origins of drumstick tree (Moringa oleifera Lam.) leaves, J. Agric. Food Chem., 51: 2144.

Sesso, H.D., J.M. Gaziano, S. Liu and J.E. Buring (2003). Ame. J. Clin. Nutr., 77: 1400 -1408 .

Shi, H.L., N. Noguchi and E. Niki (2001). Introducing Natural Antioxidants. In J. Pokorny et al. (Eds.) (2001). Antioxidants in Food: Practical Applications. Woodhead Publishing Ltd. and CRC Press.

Shan, B.Y.Z., M.S. Cai and H. Corke (2005). Antioxidant capacity of 26 spice extracts and characterization of their phenolic constituents, J. Agric. Food Chem., 53: 7749.

Steel, R.G. and J.H. Torrie (1980). Principles and Procedure of Statistics Analysis. Biometrical Approach. $2^{\text {nd }}$ Ed. MC GrawHill Book Co. INC New York, NY.

Vieira, F.G.K, G.D. Silva, C. Copetti and P. Faria (2011). Da Costa E and Fett R, Scientia Hort., 128 (3): 261-266.

\section{النشاط المضاد للأكسدة لمستخلصات قثور التفاح المحضرة بمذيبات مختلفة}

$$
\text { قسم علوم وتكنولوجيا الأغذية - كلية الزراعة - جامعة الأزهر - القاهرة - مصر }
$$

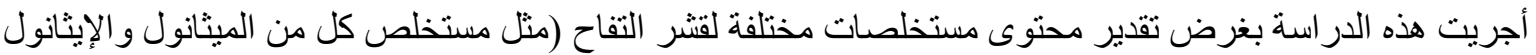

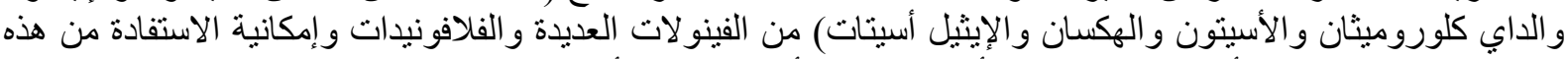

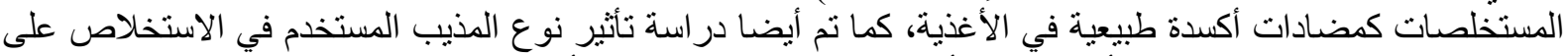

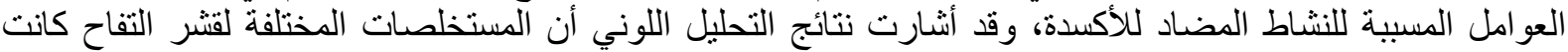

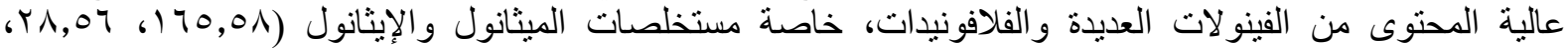

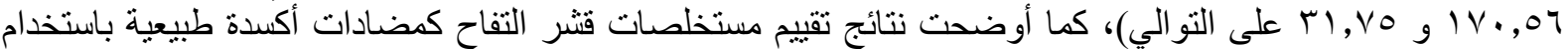

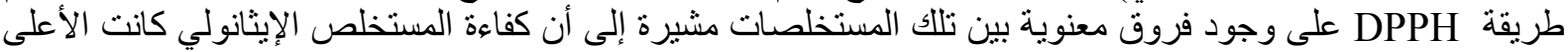
مقارنة بالمستخلصات الأخرى 